\title{
EFEITO DE TRÊS DECLIVIDADES DE BANCADA SOBRE A PRODUÇÃO DE ALFACE NO SISTEMA HIDROPÔNICO
}

\section{COUNTERTOP SLOPE EFFECT ON LETTUCE PRODUCTION IN THE HYDROPONIC SYSTEM}

\author{
Ana Paula Pinheiro Vieira \\ Acadêmica do curso de Agronomia da Faculdade Alfa-Unipac de Teófilo Otoni/MG, \\ E-mail:paulapv32@gmail.com
}

Carlos Ruas Reis

Acadêmico do curso de Agronomia da faculdade Alfa-Unipac de Teófilo Otoni/MG Email: carlos ruas1@msn.com

Omar Freitas dos Santos Junior Acadêmico do curso de Agronomia da faculdade Alfa- Unipac de Teófilo Otoni/MG Email:Jequi.junior@yahoo.com

Werner Kriebel

Docente Especialista da Faculdade Alfa-Unipac de Teófilo Otoni/MG, Brasil, E-mail: kriebel275@hotmail.com

Recebido: 20/05/2021 - Aceito: 20/05/2021

\section{Resumo}

Nos últimos anos o cultivo de alface hidropônico vem crescendo principalmente pelo crescimento populacional e a grande demanda por alimento, que a cada dia será ainda maior. Dentre as tecnologias que vêm sendo aplicadas, a hidroponia tem se destacado pela melhoria das hortaliças, mas também pela maior produtividade em grande e pequena escala. Neste sistema é necessário uma certa declividade da bancada ou das calhas de cultivo para que as plantas recebam adequadamente 0 fluxo nutritivo necessário. A velocidade da solução nutritiva, por sua vez, tem grande influência na absorção pelas raízes. Algumas pesquisas já foram feitas sobre a declividade ideal, mas outros fatores, como umidade e temperatura, também influenciam dependendo da região. Este trabalho pretende avaliar a efeito da declividade da bancada sobre o desenvolvimento de alface cv. Caipira em três declividades $2 \%, 4 \%$ e $6 \%$ em delineamento de blocos totalmente casualizados (DBC)com 3 repetições e 20 plantas por parcelas. Foi avaliado a massa fresca da planta inteira, da parte herbácea e da raiz, sendo realizado o teste de variância com fator duplo sem repetições para a comparação das médias. Os resultados mostraram que o tratamento de $2 \%$ de declividade apresentou maior produção de massa fresca e massa foliar.Estatisticamente para massa da raiz não houve diferença significativa entre os tratamentos de $2 \%, 4 \%$ e $6 \%$.

Palavras chave: Hidroponia; declividade do perfil; solução nutritiva. 


\section{Abstract}

In recent years, hydroponic lettuce has been growing mainly due to the increase in population and the great demand for food, which will be even greater each day, among the technologies that have been applied to hydroponics, it has stood out for the improvement of vegetables, but also for the greater productivity on a large and small scale. In this system, a certain slope is necessary for the plants to properly receive the necessary nutrient flow, the speed in turn has a great influence on the absorption by the roots. Some research has already been done on the ideal slopes, but how other factors like humidity and temperature also influence depending on the region. This work aimed to evaluate the effect of the slope of the bench on the production of free lettuce in the slopes of $2 \%, 4 \%$ and $6 \%$ completely randomized block design with 9 repetitions and 20 plants per plot. The fresh mass of the aerial part and the root was evaluated, the variance test of the ANOVA double factor was performed without repetitions to compare the means. The results showed that the treatment of $2 \%$ showed higher production of fresh mass and leaf mass statistically for root mass, there was no significant difference between treatments of $4 \%$ and $6 \%$.

Keywords: hydroponics; profile declivity; nutritive solution.

\section{Introdução}

Diversos fatores motivaram a realização desse trabalho relacionado à produção hidropônica. Em tempos onde o consumo de água pela agricultura é discutido, o cultivo em hidroponia propõe o menor uso de recursos hídricos evitando desperdícios com irrigação, os fertilizantes não lixiviam no solo como ocorre no sistema tradicional não havendo desperdício e contaminação do lençol freático por ser um ambiente protegido, haverá maior controle da temperatura e umidade do ar, oque fará com que a planta sofra menos estresse e ataque de pragas e doenças diminuindo consideravelmente a utilização de agrotóxicos e sem desenvolvimento de ervas invasoras e com consequentemente redução na mão de obra necessária. Já foi observado um maior tempo de conservação das hortaliças oriundas de cultivo hidropônico, não só no comércio, mas também na geladeira doméstica. Em relação

à declividade da bancada de cultivo existe pouca literatura que fala sobre o assunto.

Portanto, procurou-se desenvolver o trabalho baseado em dois artigos.

Em um artigo que avaliou quatro declividades de bancada (3\%, 4\%, 5\% e 6\%), Araújo et al.(2018) concluíram que o melhor resultado obtido o da alface tipo americana (cv. Gloriosa) foi entre 4\% e 5\% em que se observou um desempenho satisfatório entre a evolução das partes aérea e raiz. Calculou-se ainda que adeclividade de bancada a 4,3\% é a declividade de máxima produção de massafresca da parte aérea da alface tipo americana (cv. Gloriosa). 
Em outro artigo, que avaliou duas declividades (2\% e 10\%) concluiu-se que em comparação com as cultivares testadas, não houve diferença quanto à matéria fresca da raiz. Porém, a cultivar Vanda proporcionou menores resultados para matéria fresca da parte aérea e para matéria fresca total, demonstrando uma menor adaptação às condições em que foi realizado o experimento. Com relação aos fatores estudados declividade e cultivar não houve interação(PRADO;FERREIRA e MENDONÇA,_).

O termo hidroponia deriva de duas palavras gregas: hydro, água, e ponos, trabalho. A combinação dessas duas palavras significa "trabalhar com a água" $e$, implicitamente, o uso de soluções de adubos químicos para se criar plantas sem terra. Este significado opõe-se à agricultura convencional, que poderia ser denominada de "geoponia" (geo = terra)(DOUGLAS, 1987).

Segundo Rodrigues (1997)produção hidropônica é a produção fora do solo. Neste contexto engloba a produção em recipientes com substratos sólidos como exemplo a fibra de coco, ou a produção em circuitos fechados com circulação de soluções nutritivas (NFT). O NFT (Nutrient Film Technique), técnica empregada no presente estudo, consiste no cultivo em uma lâmina de água onde são acrescentados todos os nutrientes necessários ao desenvolvimento da planta em bancadas, geralmente compostas por canos de PVC com suporte para diversas cultivares.

Na hidroponia várias hortaliças têm demonstrado um desenvolvimento satisfatório, a cultura da alface tem demonstrado maior aceitação por parte dos consumidores.Com o passar do tempo, a alface se tornou uma cultura econômica de grande expressão no mercado de horticultura brasileiro, isso vem possibilitando diversos estudos sobre a cultura.

Segundo Furlani et al. (1999), no Brasil, tem crescido nos últimos anos o interesse pelo cultivo hidropônico, predominando o sistema NFT (Nutrient Film Technique). No Vale do Mucuri (Minas Gerais), poucos produtores adotam o cultivo hidropônico. Fatores como alto custo de implantação aliado ao baixo nível tecnológico da região ainda servem de grande entrave para um maior desenvolvimento da técnica, levando o produtor a optar pelo sistema de cultivo tradicional. Ao longo dos últimos 
anos, é possível constatar uma evolução na recomendação quanto às declividades adotadas para o sistema NFT, composto basicamente de um tanque de solução nutritiva, de um sistema de bombeamento, dos canais de cultivo e de um sistema de retorno ao tanque. A solução nutritiva é bombeada aos canais e escoa por gravidade formando uma fina lâmina de solução que irriga as raízes (FIG. 1).

A declividade é um dos fatores que influenciam na produção hidropônica, tanto no desenvolvimento das raízes como no desenvolvimento da parte aérea da planta. Sendo assim, esse estudo busca analisar três declividades no sistema NFT com o objetivo de encontrar a melhor opção para a alface da cultivar Caipira.

FIGURA 1 - Esquema de cultivo hidropônico no sistema NFT

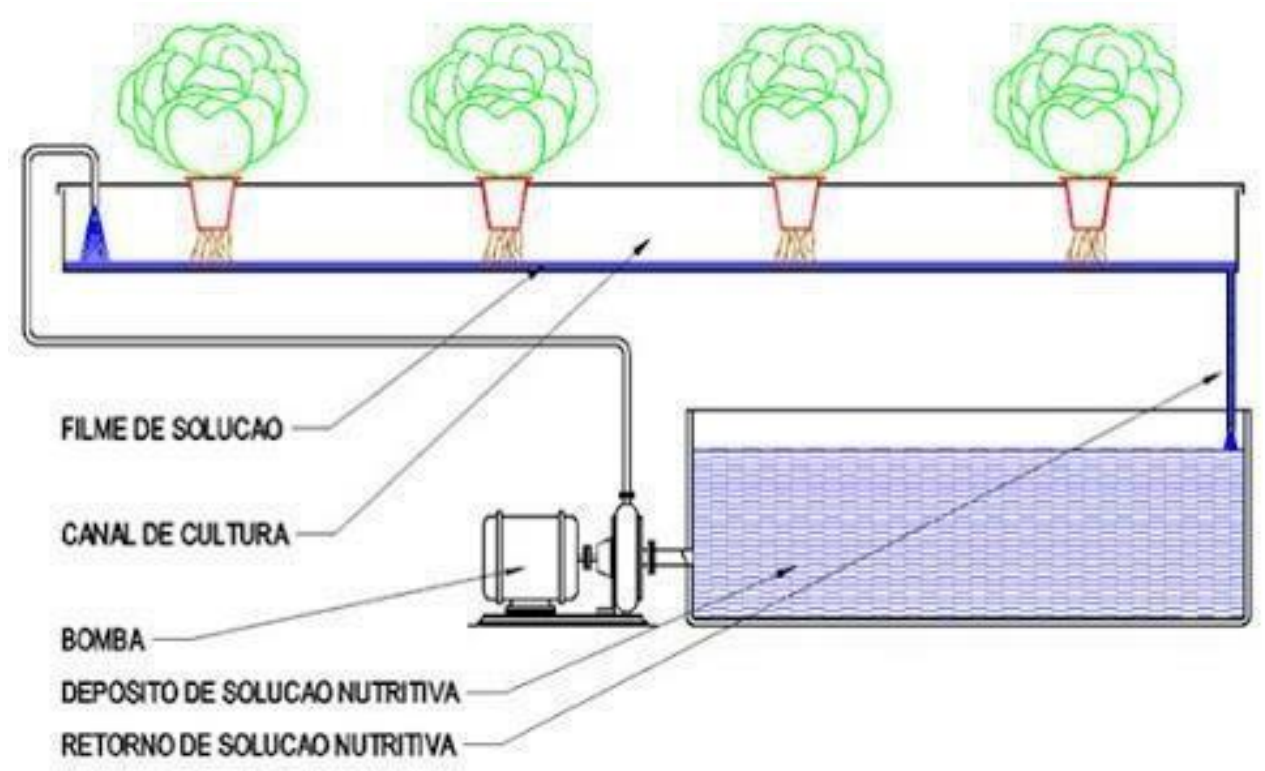

Fonte: Sistema de Aquaponia (Saulo Duarte de Oliveira)

\subsection{Objetivos Gerais}

Avaliar os efeitos da declividade da bancada sobre o desenvolvimento das raízes e da parte aérea de alface (cultivar caipira) no cultivo hidropônico. 


\subsection{Objetivos Específicos}

I. Avaliar o efeito de três diferentes declividades (2\%, 4\% e 6\%) no sistema NFT para a produção de alface da variedade Caipira.

II. Avaliar a massa fresca das raízes e da parte aérea da alface.

\section{Revisão Bibliográfica}

De acordo com Beninni et al. (2003), A declividade da bancada é um aspecto importante na produção hidropônica, objetivo de estudo de várias pesquisas.

De acordo com Furlani et al. (1999) na década de 90 a recomendação da declividade a ser adotada em sistemas hidropônicos NFT era entre 2 e 4\%, com comprimento máximo de bancada de $12 \mathrm{~m}$., assim a bancada iniciava com altura de $0.5 \mathrm{~m}$ e finalizava com $0.98 \mathrm{~m}$ (diferença de $0.48 \mathrm{~m}$, considerando-se $4 \%$ de declividade, com a implantação do sistema em um terreno plano). Atualmente recomenda-se a instalação da bancada com a declividade variando entre 8 a 10\% e comprimento máximo de 12m, gerando assim um problema na altura da bancada na extremidade na qual é injetada a solução nutritiva devido à altura considerando-se 10\% de declividade(ARAÚJO et al. , 2018).

Rodrigues (2002) afirma que para um bom desenvolvimento do sistema radicular, a bancada dos canais deve apresentar declividade suficiente para permitir o fluxo de solução ao longo de todo comprimento do canal.Como o terreno da estufa onde foi realizado o experimento é praticamente plano, seria inviável trabalharmos com declividades entre $10 \%$ e $15 \%$, pois, essas duas declividades deixariam a bancada muito íngreme. Assim decidiu-se realizar o estudo com as declividades de $2 \%, 4 \%$ e $6 \%$, reduzindo também o comprimento dos perfis de cultivo para $5,20 \mathrm{~m}$.

Segundo Douglas(1997), a solução nutritiva é a parte mais notável do cultivo hidropônico, pois substitui uma das funções mais importantes do solo: a de fornecer nutrientes para o desenvolvimento da produção vegetal, exercendo uma função imprescindível na determinação da qualidade e desempenhando uma alta 
produtividade. No sistema hidropônico, os nutrientes são disponibilizados às culturas na forma de soluto, preparado com sais fertilizantes ou adubos químicos.

A solução nutritiva que utilizamos nesse trabalho segue as recomendações do fabricante dos adubos químicos para a cultura da alface, e a quantidade desses adubos foi determinada pelo volume da caixa d'água, que nesse caso era de 4.500litros. A TAB. 1 traz a composição recomendada pelo fabricante e utilizada nesse trabalho.

Tabela 1 - Solução nutritiva inicial para 4.500 litros

\begin{tabular}{|l|c|}
\hline \multicolumn{1}{|c|}{ Produto } & Quantidade (Gramas) \\
\hline Drisol Alface & 3.205 \\
\hline Ferro & 85 \\
\hline Nitrato de Cálcio & 2.350 \\
\hline
\end{tabular}

1 O Drisol é composto com todos os macronutrientes: Nitrogênio $(N)$, Fósforo $(P)$, Potássio(K), Magnésio (Mg), Enxofre (S)e micronutrientes: Boro (B), Cobre (Cu),Molibdênio (Mo), Manganês (Mn) e Zinco (Zn).

Segundo Furlani (1999), para que haja sucesso e bom desenvolvimento da cultura hidropônica se faz necessária uma constante manutenção da concentração de nutrientes na solução. Os principais elementos para o crescimento da planta devem sempre estar presentes na solução fornecida, respeitando uma amplitude de variação que se distancie da falta (deficiência) ou do excesso de minerais (toxidez). Paralelo a esses cuidados com os elementos químicos, existem ainda dois fatores primordiais, responsáveis pelo sucesso na hidroponia: a condutividade elétrica (CE)e o potencial hidrogeniônico $(\mathrm{pH})$ da solução.

Após o preparo da solução nutritiva, foram aferidos a CE (condutividade elétrica) e o $\mathrm{pH}$ (potencial de hidrogênio). Esse processo é fundamental para que todos os parâmetros da solução nutritiva estejam em sua normalidade a fim de evitar carências ou excessos nutritivos.

De acordo com Martinez (1997), durante a absorção de nutrientes pelas plantas de alface cultivadas hidroponicamente, ocorre uma diminuição de todos os elementos da solução nutritiva, refletindo, portanto, na CE. Existe muita controvérsia com relação ao melhor valor de condutividade elétrica a ser adotado para o cultivo da 
alface em hidroponia. Acredita-se também que esses valores devem variar de acordo com a cultivar adotada, bem como com as condições climáticas. Foram adotados como parâmetros no experimento: CE de 1,4 miliSiemens/cm (mS/cm)e pH6,5.

De acordo com Teixeira (1996) não existe e não é possível criar uma solução nutritiva que atenda às necessidades de todas as espécies de vegetais e condições de cultivo. Cada espécie vegetal necessita de uma quantidade específica de nutrientes. Existem vários fatores a serem considerados na nutrição de plantas como, por exemplo, o estágio de crescimento, a estação do ano, a espécie de plantacultivada. Assim, a alface precisa de mais nitrogênio que o tomate. Outros fatoressão a parte da planta que será colhida, a temperatura e a intensidade de luz(FURLANI, 1999).

Segundo CERMEÑO (1990), os fatores que influenciam a temperatura no interior de uma estufa são o tipo de material utilizado na cobertura externa da estufa, temperatura do ambiente externo, luminosidade e vento. Segundo Villela Júnior et al.(2004), para evitar problemas na oxigenação e consequentes perdas do sistema radicular por apodrecimento devido a elevações de temperatura, um sistema eficiente não deve apresentar temperaturas acima de $30^{\circ} \mathrm{C}$.

A cidade de Teófilo Otoni no Vale do Mucuri, está situada na região Nordeste de Minas Gerais, sendo temperaturas acima de $30^{\circ} \mathrm{C}$ bastante comuns nessa região no verão (GRAF. 1).Soma-se a isto o fato de que a temperatura no interior da estufa tende a ser mais alta que no ambiente externo, aquecendo a solução nutritiva. 


\section{Gráfico 1 - Médias mensais de temperaturas em Teófilo Otoni}

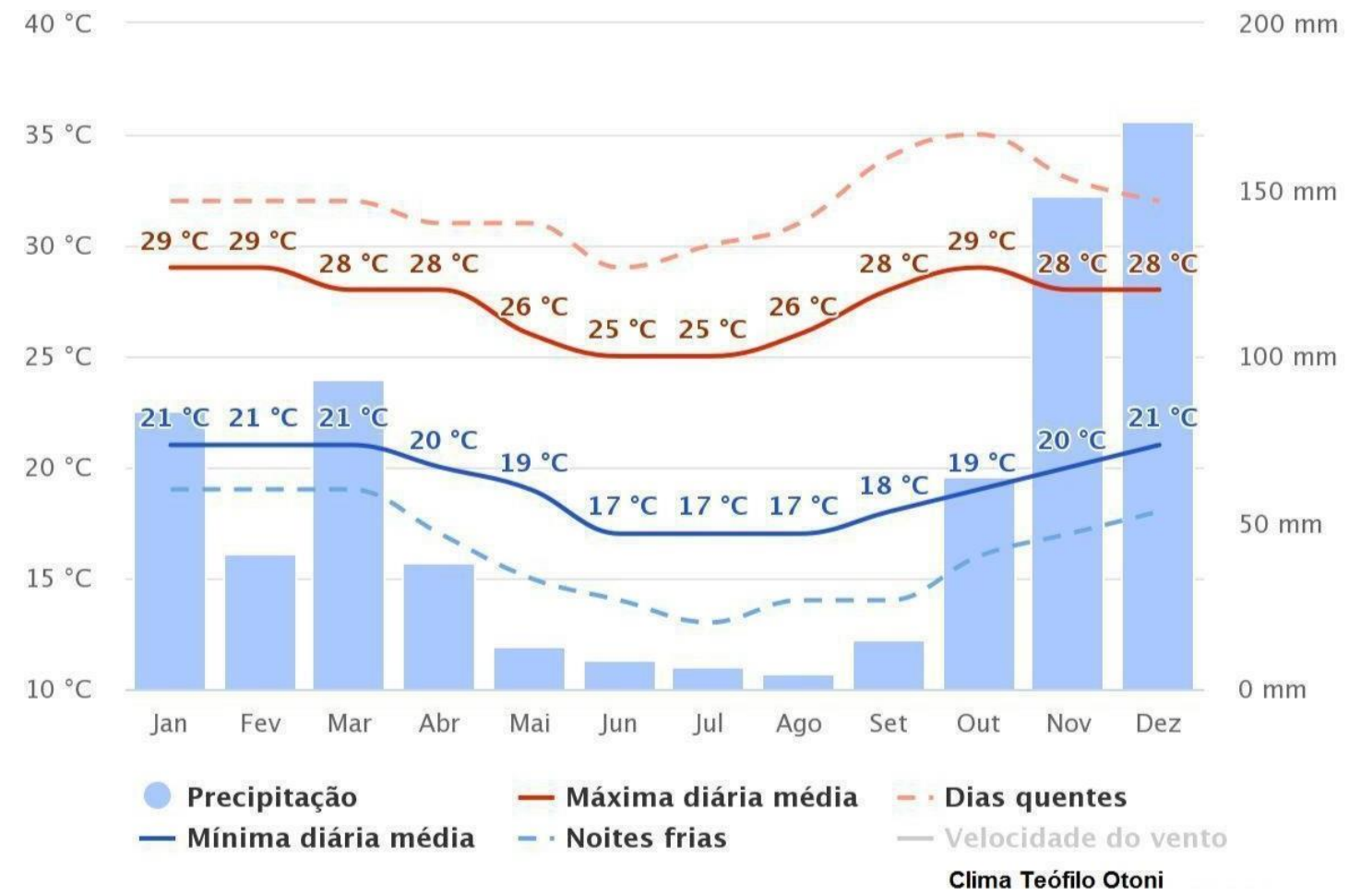

Fonte: www.meteoblue.com

Durante o experimento procurou-se aferir diariamente a temperatura dentro da estufa em três horários (manhã e tarde)encontrando-se uma variação de temperatura do arque vai de: $22,88^{\circ} \mathrm{C}$ na parte da manhã entre $7: 00$ às $8: 00 h ; 29,83^{\circ} \mathrm{C}$ entre $10: 00$ às $11: 00 \mathrm{~h}$ e de $34,85^{\circ} \mathrm{C}$ entre 13:00às 14:00 h. No períodoem que as temperaturas estiveram próximas ou superiores a $30^{\circ} \mathrm{C}$ o sistema queleva a solução nutritiva até os perfis teve que ficar ligado continuamente para evitar perda de oxigenação. Temperatura alta aumenta o metabolismo da planta e consequentemente aumenta a sua necessidade de oxigênio na zona das raízes.

\section{Metodologia}

O experimento foi realizado no setor de hidroponia da Associação Educacional Evangélica Luterana. Com nome fantasia "Internato Rural”, é uma associação sem fins lucrativos com sede na cidade de Teófilo Otoni, estado de Minas Gerais, localizada nas coordenadas: Longitude $41^{\circ} 29^{\prime} 0,30^{\prime \prime} \mathrm{W}$, Latitude $17^{\circ} 52^{\prime} 03^{\prime \prime} \mathrm{S}$ e de $354 \mathrm{~m}$ acima do nível do mar. O clima é tropical, com muito menos pluviosidade no inverno que no verão. De acordo com Köppen e Geiger o clima é classificado como 
Aw. A temperatura média é de $23.2^{\circ} \mathrm{C}$, e a média anual de pluviosidade é de 1.081 $\mathrm{mm}$.

A semeadura foi realizada no dia 11/09/2020 foram utilizadas sementes de alface peletizadas da cultivar caipira. As mudas foram produzidas em espuma fenólica com cubos de 2x2x2 cm. Nas primeiras 24 horas as placas de espuma já semeadas foram mantidas em local escuro irrigando-se apenas com água até a emergência das plântulas, quatro dias após a semeadura. No dia 16/09/2020 foram levadas para a bancada de germinação onde ficaram por seis dias. No dia 22/09/2020 foram transplantadas para o berçário em ambiente protegido e conduzidas pela técnica do sistema NFT, onde ficaram por mais seis dias, sendo logo após transplantadas para os perfis de crescimento da fase final de desenvolvimento, onde permaneceram até a colheita com 25 Dias (QUADRO 1).

\section{Quadro 1 - Etapas do experimento (idades em DAE = dias após emergência)}

\begin{tabular}{|l|c|}
\hline Etapas & Idade das plantas (DAE) \\
\hline Semeadura & -4 dias \\
\hline Emergência & 0 dias \\
\hline Transplantio para berçário & dias \\
\hline Transplantio para perfil de crescimento & 31 dias \\
\hline Colheita & dias \\
\hline
\end{tabular}

Fonte: dados do experimento

Durante o desenvolvimento da cultivar, utilizou-se uma solução nutritiva seguindo as recomendações do fabricante com: $3,205 \mathrm{~kg}$ de Drisol alface, $85 \mathrm{~g}$ de quelato de ferro e 2,350 kg de nitrato de cálcio, a CE (condutividade elétrica) da solução ficou a 1,4 miliSiemens/cm e o pH 6,5para 4.500 litros de água (TAB. 1). Durante essa etapa, a sequência de irrigação da solução nutritiva foi controlada por um timer que funcionava na parte da manhã de 6:00 ás 10:30 alternado de 15 em 15 minutos, de 10:30 ás 16:45 continuamente, de 16:45 ás 20 alternado de 15 em 15 minutos, de 20ás 22:30 fica desligado, das 22:30 liga permanecendo por 30 minutos ligado direto, de 23:00 até 3:00 permanece desligado, de 3:00 ás 3:30 fica ligado continuamente, de 3:30 até 6:00 permanece desligado, e as 6:00recomeça o ciclo . 
Utilizou-se o delineamento em blocos casualizados, cada tratamento com três parcelas com vinte plantas em cada sendo as parcelas submetidas às inclinações de 2\% (T1), 4\% (T2) e 6\% (T3), respectivamente. Em seguida utilizamos odelineamento em blocos casualizados, onde cada bloco (denominados $\mathrm{A}, \mathrm{B}$ ou $\mathrm{C}$ ) recebeu os três tratamentos (T1, T2 e T3). Assim, avaliou-se a alface cultivar Caipira em três declividades, sendo coletados os dados de: matéria fresca total; matéria fresca de parte aérea; matéria fresca de raiz. As pesagens foram realizadas com balança digital com precisão de $2 \mathrm{~g}$.

Após a colheita e determinação das massas foram calculadas as médias e realizada análise de variância com auxílio do programa Microsoft Excel.

A fim de manter as plantas em condições ideais de desenvolvimento, foram realizadas as seguintes atividades no decorrer do experimento: monitoramento do fluxo e aspectos nutricionais da solução nutritiva; monitoramento da condutividade elétrica (CE) da solução nutritiva; monitoramento do potencial de hidrogênio $(\mathrm{pH})$ da solução nutritiva; monitoramento dos fatores ambientais (temperatura e umidade no interior da estufa).

Durante a realização do monitoramento da CE e do $\mathrm{pH}$ no período de tratamento, foi identificada a necessidade de reajustes na solução nutritiva para a reposição dos nutrientes de acordo com as recomendações do fabricante. As medições diárias e os ajustes realizados são apresentados no ANEXO I

(ANEXO I) - ajustes diários da solução nutritiva

\begin{tabular}{|c|c|c|c|c|}
\hline Data & $\begin{array}{c}\text { CE da } \\
\text { Solução }\end{array}$ & $\begin{array}{c}\text { Correção da solução } \\
\text { Quantidades em gramas }\end{array}$ & $\mathrm{pH}$ & $\mathrm{pH}$ \\
\hline & $\mathrm{mS}$ & $\begin{array}{c}\text { Drisol alface Micro/Macro } \\
\text { Quelato de Ferro } \\
\text { Nitrato de Cálcio }\end{array}$ & $\begin{array}{c}\text { Medido } \\
\text { Diariamente }\end{array}$ & $\begin{array}{c}\text { Ajustado } \\
\text { Diariamente } \\
\text { Para: }\end{array}$ \\
\hline $22 / 09 / 2020$ & 0.95 & $1180 / 51 / 855$ & 6.5 & 6.5 \\
\hline $23 / 09 / 2020$ & 1.10 & $795 / 34 / 565$ & 6.7 & 6.5 \\
\hline $24 / 09 / 2020$ & 1.15 & $795 / 34 / 565$ & 6.0 & 6.5 \\
\hline $25 / 09 / 2020$ & 1.15 & $795 / 34 / 565$ & 6.0 & 6.5 \\
\hline $26 / 09 / 2020$ & 0.93 & $1180 / 51 / 565$ & 6.2 & 6.5 \\
\hline
\end{tabular}




\begin{tabular}{|c|c|c|c|c|}
\hline $27 / 09 / 2020$ & 1.30 & CE IDEAL & 7.0 & 6.5 \\
\hline $28 / 09 / 2020$ & 1.29 & CE IDEAL & 6.8 & 6.5 \\
\hline $29 / 09 / 2020$ & 1.30 & CE IDEAL & 6.3 & 6.5 \\
\hline $30 / 09 / 2020$ & 1.15 & $795 / 34 / 565$ & 6.0 & 6.5 \\
\hline $01 / 10 / 2020$ & 0.97 & $795 / 34 / 565$ & 6.7 & 6.5 \\
\hline $02 / 10 / 2020$ & 0.90 & $1180 / 51 / 855$ & 6.5 & 6.5 \\
\hline $03 / 10 / 2020$ & 0.78 & $1180 / 51 / 855$ & 6.1 & 6.5 \\
\hline $04 / 10 / 2020$ & 1.30 & CE IDEAL & 6.3 & 6.5 \\
\hline 05/10/2020 & 1.18 & $795 / 34 / 565$ & 7.0 & 6.5 \\
\hline $06 / 10 / 2020$ & 1.29 & CE IDEAL & 6.9 & 6.5 \\
\hline $07 / 10 / 2020$ & 1.22 & $395 / 17 / 280$ & 6,5 & 6.5 \\
\hline $08 / 10 / 2020$ & 1.09 & $795 / 34 / 565$ & 6.6 & 6.5 \\
\hline $09 / 10 / 2020$ & 1.02 & $795 / 34 / 565$ & 6.0 & 6.5 \\
\hline $10 / 10 / 2020$ & 1.10 & $795 / 34 / 565$ & 6.1 & 6.5 \\
\hline $11 / 10 / 2020$ & $\ldots$ & Sem correção & 6.2 & 6.5 \\
\hline $12 / 10 / 2020$ & 0.90 & $1180 / 51 / 855$ & 6.2 & 6.5 \\
\hline $13 / 10 / 2020$ & 0.95 & $1180 / 51 / 855$ & 6.2 & 6.5 \\
\hline $14 / 10 / 2020$ & 1.20 & CE IDEAL & 6.9 & 6.5 \\
\hline $15 / 10 / 2020$ & 1.18 & $795 / 34 / 565$ & 6.9 & 6.5 \\
\hline $16 / 10 / 2020$ & 1.10 & $795 / 34 / 565$ & 7.0 & 6.5 \\
\hline $17 / 10 / 2020$ & 1.11 & $795 / 34 / 565$ & 6.6 & 6.5 \\
\hline $18 / 10 / 2020$ & 1.26 & CE IDEAL & 5.98 & 6.5 \\
\hline 19/10/2020 & 1.21 & CE IDEAL & 6.1 & 6.5 \\
\hline $20 / 10 / 2020$ & 1.15 & $795 / 34 / 565$ & 6.8 & 6.5 \\
\hline $21 / 10 / 2020$ & 1.27 & CE IDEAL & 6.7 & 6.5 \\
\hline $22 / 10 / 2020$ & 0.99 & $1180 / 51 / 855$ & 6.7 & 6.5 \\
\hline $23 / 10 / 2020$ & 1.20 & CE IDEAL & 6.5 & 6.5 \\
\hline
\end{tabular}

Fonte: dados obtidos durante o experimento.

\section{Resultados e discussão}

Nesse experimento foram analisados três tratamentos com as declividades dos perfis de $2 \%, 4 \%$ e $6 \%$.Através das tabelas podemos observar que houve diferença significativa em relação aos tratamentos T1,T2 e T3 para o valor da massa total e 
para a massa da parte aérea, essa diferença pode ser notada pela diferença significativa no tratamento 1 na declividade de $2 \%$ que obteve o maior peso total e massa foliar.

A TAB. 2 apresenta as médias de produção de massa fresca total obtidas nos três tratamentos.

Tabela 2 - produção de massa fresca total nos três tratamentos

\begin{tabular}{ccc|ccc|cccc}
\hline \multicolumn{3}{c}{ T 2\% } & \multicolumn{3}{c|}{ T 4\% } & \multicolumn{3}{c}{ T 6\% } \\
\hline \multicolumn{3}{c|}{ Total } & \multicolumn{3}{c|}{ Total } & \multicolumn{3}{c}{ Total } \\
\hline A & D & G & B & E & H & C & F & I \\
\hline 396 & 311 & 249 & 282 & 292 & 294 & 302 & 234 & 322 \\
314 & 321 & 314 & 280 & 226 & 248 & 240 & 258 & 275 \\
264 & 261 & 283 & 210 & 191 & 242 & 203 & 216 & 202 \\
270 & 310 & 311 & 269 & 194 & 232 & 224 & 154 & 213 \\
344 & 307 & 271 & 264 & 234 & 287 & 156 & 195 & 252 \\
\hline 317.6 & 302 & $\mathbf{2 8 5 . 6}$ & $\mathbf{2 6 1}$ & $\mathbf{2 2 7 . 4}$ & $\mathbf{2 6 0 . 6}$ & $\mathbf{2 2 5}$ & $\mathbf{2 1 1 . 4}$ & $\mathbf{2 5 2 . 8}$ \\
\hline Médias & 301.7 & \multicolumn{3}{c|}{249.7} \\
\hline
\end{tabular}

Fonte: dados obtidos no experimento.

( ANEXO 2) apresenta a análise de variância realizada.

Tabela 3

\begin{tabular}{|c|c|c|c|c|c|c|c|c|c|c|}
\hline \multicolumn{7}{|c|}{ Anova: fator duplo sem repetição } & & & \\
\hline RESUMO & & tarem & $\mathrm{SO}_{\mathrm{s}}$ & & & odia & Var & ância & & \\
\hline $\mathrm{B} 1$ & 3 & & 803 & & & 7.8667 & 217 & 9.053 & & \\
\hline$\overline{\mathrm{B} 2}$ & 3 & & 740 & & & 6,9333 & 233 & 8,253 & & \\
\hline B3 & 3 & & 799 & & & 6,3333 & 293 & 6133 & & \\
\hline T1 & 3 & & 905 & & & 1,7333 & 256 & 0533 & & \\
\hline T2 & 3 & & 749 & & & 9,6667 & 371 & 8933 & & \\
\hline T3 & 3 & & $68 \mathrm{c}$ & $\overline{9,2}$ & & 9,7333 & 445 & 2933 & & \\
\hline ANOVA & & & & & & & & & & \\
\hline $\begin{array}{l}\text { Fonte } \\
\text { variação }\end{array}$ & & $S Q$ & & $g l$ & & $M Q$ & & $F$ & valor-P & F crítico \\
\hline Linhas & & 816,91 & & 2 & & $\overline{408,4}$ & 578 & 1,228847 & 0,383676 & 6,944272 \\
\hline Colunas & & 8292,2 & & 2 & & 4146 , & 138 & 12,47367 & 0,019094 & 6,944272 \\
\hline Erro & & 1329,5 & & 4 & & 332,3 & 911 & & & \\
\hline Total & & 10438 & & 8 & & & & & & \\
\hline
\end{tabular}


Na tabela 3 percebe-se que houve uma diferença significativa (a $5 \%$ ) para a produção de massa total, no qual o tratamento 1 na declividade de $2 \%$ sobressaiu. $O$ tratamento 3 na declividade de $6 \%$ foi o tratamento com o menor desempenho em relação aos demais. Pela declividade mais acentuada a velocidade em que a solução nutritiva passa pelas raízes influencia na absorção dos nutrientes, no tratamento 3 pode ter ocorrido uma baixa absorção pelas raízes por isso o baixo desenvolvimento.

A TAB.4 apresenta as médias de produção de massa fresca das raízes nos três tratamentos.

Tabela 4 - produção de massa fresca das raízes nos três tratamentos

\begin{tabular}{|c|c|c|c|c|c|c|c|c|c|}
\hline \multicolumn{4}{|c|}{ T 2\% } & \multicolumn{3}{|c|}{ T 4\% } & \multicolumn{3}{|c|}{ T 6\% } \\
\hline \multicolumn{4}{|c|}{ Raiz } & \multicolumn{3}{|c|}{ Raiz } & \multicolumn{3}{|c|}{ Raiz } \\
\hline \multirow[t]{7}{*}{$\bar{A}$} & D & & & $B$ & $E$ & & C & & \\
\hline & 40 & 40 & 37 & 41 & 39 & 39 & 42 & 29 & 44 \\
\hline & 37 & 41 & 38 & 36 & 30 & 34 & 38 & 33 & 34 \\
\hline & 37 & 41 & 38 & 30 & 27 & 33 & 33 & 30 & 32 \\
\hline & 36 & 40 & 41 & 35 & 29 & 30 & 34 & 24 & 34 \\
\hline & 42 & 43 & 31 & 39 & 33 & 35 & 25 & 30 & 34 \\
\hline & 38,4 & 41 & 37 & 36,2 & 31,6 & 34,2 & 34,4 & 29,2 & 35,6 \\
\hline & 38,8 & & & & 34,0 & & & 33,1 & \\
\hline
\end{tabular}

Fonte: dados obtidos no experimento.

Tabela 5 - apresenta a análise de variância realizada sobre a massa fresca da raiz.

\begin{tabular}{|l|l|l|l|l|}
\hline \multicolumn{4}{|l|}{ Anova: fator duplo sem repetição } & \\
\hline & & & & \\
\hline RESUMO & Contagem & Soma & Média & Variância \\
\hline B1 & 3 & 109 & 36,33333 & 4,013333 \\
\hline B2 & 3 & 101,8 & 33,93333 & 38,89333 \\
\hline B3 & 3 & 106,8 & 35,6 & 1,96 \\
\hline & & & & \\
\hline T1 & 3 & 116,4 & 38,8 & 4,12 \\
\hline
\end{tabular}




\begin{tabular}{|l|l|l|l|l|l|l|l|l|}
\hline T2 & 3 & 102 & 34 & 5,32 & \\
\hline T3 & 3 & \multicolumn{1}{|l|}{99,2} & 33,06667 & 11,57333 & \\
\hline ANOVA & & & & & & & \\
\hline $\begin{array}{l}\text { Fonte } \\
\text { da } \\
\text { variação }\end{array}$ & $S Q$ & $g l$ & $M Q$ & $F$ & valor-P & F crítico \\
\hline Linhas & 9,075556 & 2 & 4,537778 & 0,55085 & 0,614738 & 6,944272 \\
\hline Colunas & 56,78222 & 2 & 28,39111 & 3,446453 & 0,134844 & 6,944272 \\
\hline Erro & 32,95111 & 4 & 8,237778 & & & \\
\hline Total & 98,80889 & 8 & & & & & \\
\hline
\end{tabular}

Pelos dados apresentados na TAB. 5 conclui-se que não houve diferença significativa em relação à massa fresca do sistema radicular.

A TAB. 6 apresenta as médias e a TAB. 7 traz a análise de variância realizada da massa fresca da parte aérea.

\begin{tabular}{|c|c|c|c|c|c|c|c|c|}
\hline \multicolumn{3}{|c|}{ T $2 \%$} & \multicolumn{3}{|c|}{ T 4\% } & \multicolumn{3}{|c|}{ T 6\% } \\
\hline \multicolumn{3}{|c|}{ Folhas } & \multicolumn{3}{|c|}{ Folhas } & \multicolumn{3}{|c|}{ Folhas } \\
\hline A & D & G & B & & $\mathrm{H}$ & C & & I \\
\hline 356 & 272 & 212 & 241 & 252 & 255 & 260 & 205 & 278 \\
\hline 277 & 280 & 276 & 244 & 196 & 214 & 202 & 225 & 241 \\
\hline 227 & 220 & 245 & 180 & 164 & 209 & 170 & 186 & 170 \\
\hline 234 & 270 & 270 & 234 & 165 & 202 & 190 & 130 & 179 \\
\hline 302 & 264 & 240 & 225 & 201 & 252 & 131 & 165 & 218 \\
\hline 279,2 & 261,2 & 248,6 & 224,8 & 195,6 & 226,4 & 190,6 & 182,2 & 217,2 \\
\hline Médias & 263,0 & & & 215,6 & & & 196,7 & \\
\hline
\end{tabular}

Fonte: dados obtidos no experimento. 
Tabela 7 - análise da massa fresca da parte aérea

\begin{tabular}{|c|c|c|c|c|c|c|}
\hline \multicolumn{5}{|c|}{ Anova: fator duplo sem repetição } & & \\
\hline RESUMO & Contagem & Soma & Média & Variância & & \\
\hline B1 & 3 & 694,6 & 231,5333 & 1996,493 & & \\
\hline B2 & 3 & 639 & 213 & 1787,32 & & \\
\hline B3 & 3 & 691,6 & 230,5333 & 249,9733 & & \\
\hline$\overline{T 1}$ & 3 & 788,4 & 262,8 & 245,28 & & \\
\hline T2 & 3 & 646,8 & 215,6 & 300,64 & & \\
\hline T3 & 3 & 590 & 196,6667 & 333,8533 & & \\
\hline \multicolumn{7}{|l|}{ ANOVA } \\
\hline $\begin{array}{l}\text { Fonte da } \\
\text { variação }\end{array}$ & $S Q$ & $g l$ & $M Q$ & $F$ & valor-P & Fcrítico \\
\hline Linhas & 651,9022 & 2 & 325,9511 & 1,177097 & 0,396277 & 6,944272 \\
\hline Colunas & 6959,929 & 2 & 3479,964 & 12,56708 & 0,01885 & 6,944272 \\
\hline Erro & 1107,644 & 4 & 276,9111 & & & \\
\hline Total & 8719,476 & $\varepsilon$ & & & & \\
\hline
\end{tabular}

Pela análise apresentada na TAB. 7. Houve uma diferença significativa para a produção de massa da parte aérea, sobressaindo-se 0 tratamento $\mathrm{T} 1=2 \%$ de declividade.

Em comparação do nosso estudo em relação aos artigos que serviram de orientação, podemos observar algumas diferenças nos resultados. No artigo que avaliou quatro declividades de bancada (3\%, 4\%, 5\% e 6\%), Araújo et al.(2018) concluíram que o melhor resultado obtido para o desenvolvimento da alface tipo americano (cv. Gloriosa) foi entre $4 \%$ e $5 \%$ em que se observou um desempenho satisfatório entre a evolução das partes aérea e raiz. Em outro artigo que avaliou duas declividades (2\% e $10 \%$ ) concluiu-se que comparando as cultivares testadas, não apresentaram diferenças estatísticas quanto à matéria fresca da raiz. Entretanto, uma cultivar apresentou os menores resultados tanto para matéria fresca da parte aérea quanto para matéria fresca total. 
Alguns fatores podem ter interferido com relação a essas diferenças, os tipos de declividade adotados, a temperatura ambiente no interior da estufa, a formulação da solução nutritiva adotada em cada experimento, a variedade das cultivares utilizadas.

\section{Conclusão}

Através do experimento realizado em sistema hidropônico com a cultivar de alface Caipira, onde foi analisada a produção de massa fresca, massa radicular e a massa da parte aérea, concluímos que os melhores resultados foram obtidos na declividade de $2 \%$ onde foi observado um desempenho satisfatório para a evolução da parte aérea e da massa total das plantas.

\section{Referências}

Blat, Sally F., et al. "Desempenho de cultivares de alface crespa em dois ambientes de cultivo em sistema hidropônico." Horticultura Brasileira 29.1 (2011): 135-138.

DE ARAÚJO, Orivaldo Maia et al. Efeito da declividade de bancada sobre a produção de alface. PUBVET, v. 12, p. 138, 2018.

DOS SANTOS BRIÃO, Fabiano. Monitoramento de um cultivo hidropônico através de um circuito de automação e controle. Caderno de Graduaçao-Ciências Exatase Tecnológicas-UNIT-ALAGOAS, v. 3, n. 1, p. 105-116, 2015.

DOUGLAS, James Sholto. Hidroponia: cultura sem-terra. NBL Editora, 1987.

Helbel Junior, Celso, et al. "Influência da condutividade elétrica, concentração iônica e vazão de soluções nutritivas na produção de alface hidropônica." Ciência e Agrotecnologia 32.4 (2008): 1142-1147.

https://files.cercomp.ufg.br/weby/up/186/o/TCC_Saulo_Duarte_de_Oliveira.pdf https://www.meteoblue.com/pt/tempo/historyclimate/climatemodelled/te\%C3\%B3filo -otoni_brasil_3446621

MATTOS, KAREN, et al. "Temperatura do ar no interior do canal de cultivo e crescimento da alface em função do material de cobertura da mesa de cultivo hidropônico-NFT." Bragantia 60.3 (2001): 253-260.

PRADO, F.E; FERREIRA, C.H; MENDONÇA, R. M. Comparação das declividades de 2 e 10\% no cultivo hidropônico de alface. Horticultura Brasileira 30: S577-S581 
Revista Multidisciplinar do Nordeste Mineiro, v.1, 2021/01

ISSN 2178-6925

Faculdade Presidente Antônio Carlos de Teófilo Otoni

FICHA DE ACOMPANHAMENTO INDIVIDUAL DE ORIENTAÇÃO DE TCC

Atividade: Trabalho de Conclusão de Curso - Artigo/Monografia.

Curso: AGRONOMIA Período: $10^{\circ}$ Semestre: $2^{\circ}$ Ano: 2020

Professor (a): Werner Kriebel

Acadêmico: Carlos Ruas Reis

Tema: EFEITO DE TRÉS DECLIVIDADES DE BANCADA SOBRE A PRODUÇÃO DE ALFACE NO SISTEMA HIDROPÔNICO

\begin{tabular}{|c|c|}
\hline Data(s) do(s) atendimento(s) & Horário(s) \\
\hline $31 / 08 / 2020$ & $17: 00-17: 30$ \\
\hline $25 / 09 / 2020$ & $9: 30-11: 00$ \\
\hline $05 / 10 / 2020$ & $16: 00-16: 30$ \\
\hline $17 / 10 / 2020$ & $16: 00-16: 40$ \\
\hline $27 / 10 / 2020$ & $9: 30-11: 00$ \\
\hline $11 / 04 / 2020$ & $16: 15-17: 30$ \\
\hline $\begin{array}{l}\text { Descriçăo das orientaçōes: } \\
\text { As orientaçōes foram feitas na maioria das vezes por meio de e-mail e whats-app, tendo sido } \\
\text { feita também uma orientação via a plataforma TEAMS da faculdade e duas orientaçōes } \\
\text { presenciais (montagem do experimento e colheita/pesagem das plantas). }\end{array}$ \\
\hline
\end{tabular}

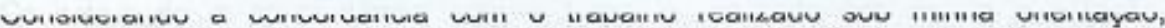

AUTORIzo O DEPÓsito do Trabalho de Conclusão de Curso do (a) Acadêmico (a) Carlos Ruas Reis.

Teófilo Otoni, $13 / 11 / 2020$

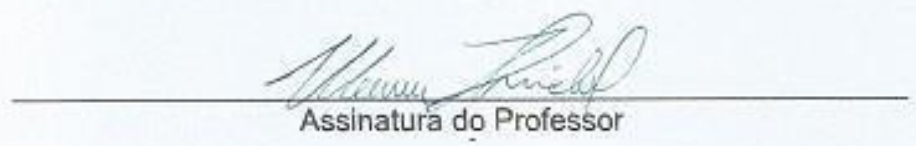


Revista Multidisciplinar do Nordeste Mineiro, v.1, 2021/01

ISSN 2178-6925

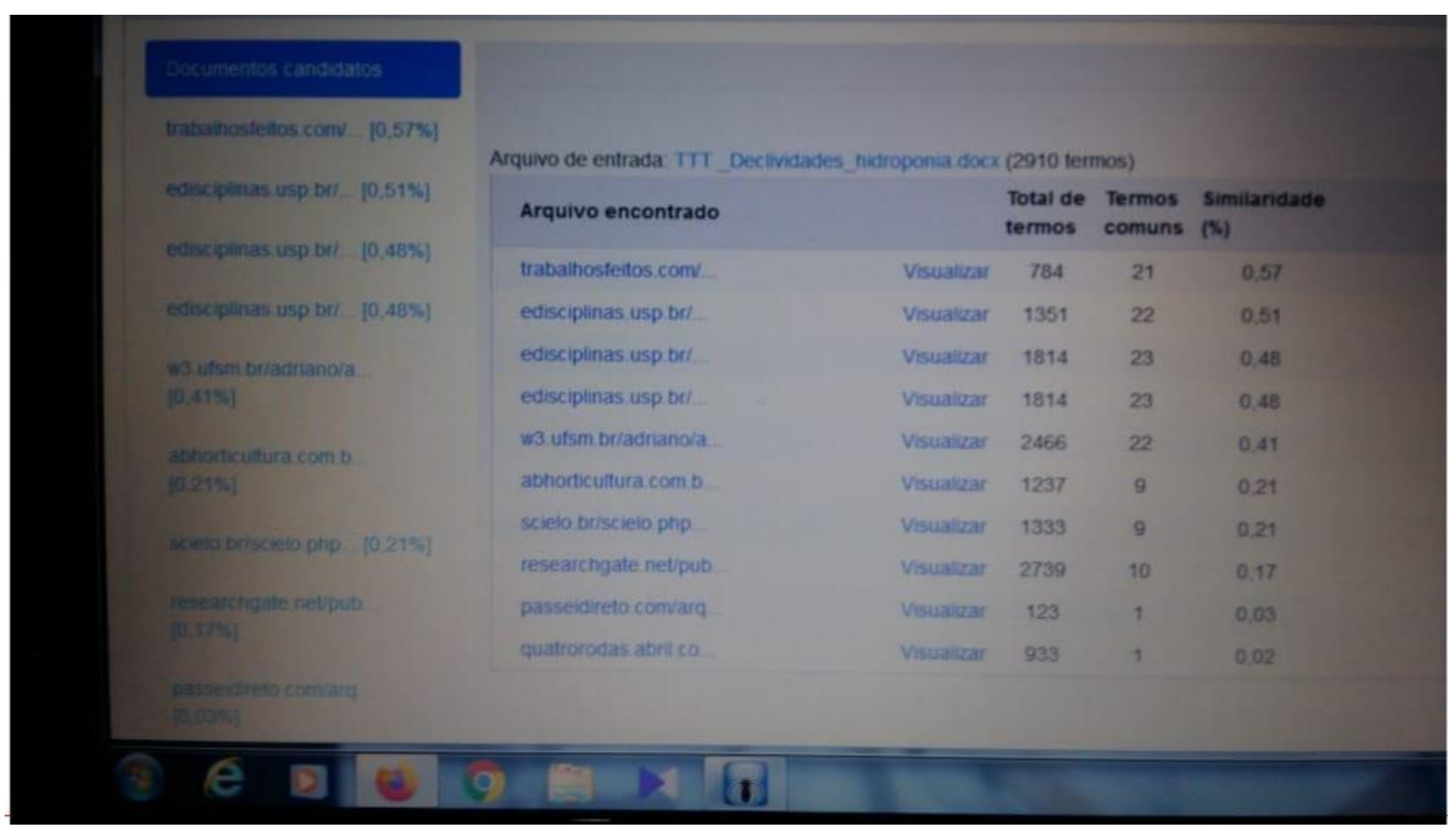

